\title{
Teacher's motivation to use play as a medium of instruction
}

\begin{abstract}
The purpose of this study was to establish the influence of pre-school teachers' level of motivation on use of play as a medium of instruction in pre-school children's learning. It aimed at finding out if there is level of motivation that can make teachers to use play as a medium of instruction and participate in children's play activities for children's learning and enjoyment. Play is essential for the learning and development of children because it contributes to the cognitive, physical, social, and emotional well-being of children. It offers an ideal opportunity for teachers to engage fully with their children. Despite the benefits derived from play for both children and teachers, time for free play has been markedly reduced for some children. The study was carried out in Masaba north District of Nyamira County Kenya. The study location has preschools of the two categories of sponsorship: public, private both in rural and urban areas. The study was aimed at understanding of when and how pre-school teachers get involved to children's play and demonstrate personal practices involving effective participation. The key finding was that teachers need motivation for them to use play as a medium of instruction. There are a number of motivators that can increase the teachers' motivation to use play as a medium of instruction and participate in children's 'play such as good salary, good management and personal convenience. The study recommended that the national and county governments as well as communities to work together to improve ECDE teachers' terms and conditions of service as well as come up with a salary scale commensurate to the teachers academic grade. Children deserve the right of free play and therefore teachers' level of motivation to use play as a medium of instruction should be encouraged to participate in children's' play.
\end{abstract}

Keywords: Play, motivation, pre-school teachers, medium of instruction, learning, good salary, good management, personal convenience, learning, development, emotional, intellectual, physical, social skills
Special Issue - 2018

\author{
Chrisanto Omwenga Manyara, Catherine \\ Gakii Murungi \\ Kenyatta University, Department of Early Childhood Studies, \\ Kenya
}

Correspondence: Catherine Gakii Murungi, Department of Early Childhood Studies, Kenyatta University, PO-43844-00I00, Nairobi, Kenya, Email Catherine_gakii@yahoo.com

Received: July 12, 2018 | Published: December 31, 2018

\section{Introduction}

\section{A. Pre-school teachers', motivation to use play as a medium of instruction for learning, enjoyment and development of children.}

Play serves an important process for promoting children's learning and development. It enhances emotional, intellectual, physical, and social skills of the child in ways that cannot be taught through formal classroom instruction. According to Nabwire \& Murungi, ${ }^{1}$ Playing a game is a way to guide children who have the basic knowledge about the world and this knowledge open them a way to the language, creative/ art, social science, mathematics and music they will learn . It is not known why in many pre-primary schools most children who are eager and curious for play are never given opportunities to fully participate in their play activities; instead they are left in class throughout the day for academic learning activities. It is not clear the level of pre-school teachers' motivation to use play as a medium of instruction in children's learning.

Play enhances language development, social competence, creativity, imagination, and thinking skills. According to Brown\& Marchan, "play is the chief vehicle for the development of imagination and intelligence, language, social skills, and perceptualmotor abilities in infants and young children". It is therefore important to note that children who do not interact through play are likely to encounter language problems. Play is most common during childhood when children's knowledge of self, comprehension of verbal and non-verbal communication, and understanding of the physical and social worlds are expanding dramatically, Mweru \& Murungi, ${ }^{3}$ These important developmental milestones of children are likely to be negatively affected if children are not given opportunity for play under the guidance of adult mostly pre-school teachers. It is not known the level of pre-school teachers' motivation to use play as a medium of instruction and participate in children's play activities.

Brown\& Marchant, ${ }^{2}$ argues that play is the "ultimate integrator of human experience". This means that when children play, they draw upon their past experiences-things they have done, seen others do, read about, or seen on television-and they use these experiences to build games, play scenarios, and engage in activities. According to Mweru \& Murungi, ${ }^{3}$ when children are given the opportunity to play, teachers are able to understand stages of development, the type of play they will get involved in and their play needs at various stages of development. This study seeks to find out the level of pre-school teachers' motivation to use play as a medium of instructions for children's learning. Children use fine and gross motor skills in their play; they react to each other socially. They think about what they are doing or are going to do. They use language to talk to each other or to themselves and they very often respond emotionally to the play activity. The integration of these different types of behaviors is key to the cognitive development of young children. ${ }^{4}$ Because children's play draws upon all of these behaviors, it is a very effective vehicle for learning. The negative of the above is likely to take place as children are not given opportunity for play under the guidance of teachers. 
Children's play has many opportunities for learning but, there is no guarantee that children will learn all they need to know through play. Providing opportunities for children to choose among wellplanned, varied learning activities enhances the probability that they will learn through play. The influence of play on children's developing cognitive capacities, including the skills has been emphasized by both Piaget and Vygotsky. ${ }^{4}$ Many teachers are aware of the importance of children's play .Reasons why the children are not given adequate opportunity to play is an issue that needs to be established: In earlier mornings before children are allowed to enter into their classrooms for learning activities and in the afternoon when almost allowed to go to their homes, they are just left to play alone without a teacher for the required instructions. Why teachers are reluctant in the participation of children's play is an issue this study seeks to establish. It is not clear if the level of pre-school teachers' motivation influence their use of play as a medium of instruction.

According to Muthee \& Murungi ${ }^{5}$ the teacher can capitalize upon the great learning potential offered to the child. He further argues that, skilful interaction can stimulate and act as a catalyst of children's play, this help focus the children's attention and set up challenges, all of which enhance and deepen the child's experiences through intervention in fantasy. This study therefore seeks to establish the level of pre-school teachers' motivation to participate in children's play and use play as medium of instruction. The pre-school years, are marked by significant changes in height, muscle strength, and body mass and proportion that allow children to move in coordinated and complex ways. According to Lock \& Lotham. ${ }^{6}$ motor coordination and play do not simply emerge in all children as part of maturation; meaning that healthy physical development is not a sure thing. The environment and the people within it play a major role in determining whether or not children will acquire important motor skills and maintain physical health. In this case teachers have a good chance of guiding children to acquire healthy physical development. Much has not been documented on the level of motivation of teachers for them to participate in children's play activities and use play as a medium of instruction.

Brown \& Marchant, ${ }^{2}$ observed that young children's motor development is a powerful predictor of cognitive abilities in the elementary years. Early gross motor abilities have been associated with several cognitive processes that are fundamental for academic learning: processing speed and memory. According to Muthee \& Murungi, ${ }^{5}$ movement facilitates the development of new connections (synapses) among brain cells and the overall organization of the brain. In schools teachers are expected to provide adequate play materials for children's play using their fine and gross motor skills and fully participate in children's play. Preschool motor play requires a great deal of communication with peers under the guidance of teachers. Children use more words and complex sentences during play than they do in other types of classroom activities. ${ }^{7}$ The sheer practice of language in play is likely to promote communicative competence. When children move, according to this perspective, they act out with their bodies the structure and meaning of words and sentences. The relationship between language and physical action can be strengthened, from this view, when teachers overlay words and phrases across children's activities.

Studies on movement and cognition suggest several ways that teachers can maximize the intellectual benefits of play. They can provide play experiences that encourage children to solve problems with their bodies. They should encourage children to reflect on their own physical behavior by asking them to move across the playground. According to Smilansky, ${ }^{7}$ Simple movement games may stimulate the frontal lobe of the brain, which is responsible for self-regulation: This is important for cognitive development of children. It is important to include motor play experiences in preschools to promote physical health. Low physical activity level in the early years predicts later health problems. Sedentary preschoolers are more likely to become obese in childhood and later as adults. Lock and Latham, ${ }^{6}$ observed that adult obesity is linked to diabetes, heart disease, and other medical conditions, sedentary behavior may impact young children's health too. Lock and Latham, ${ }^{6}$ claims that, preschool-age children who exhibit low levels of play activity are found already to have greater health risk factors, such as higher triglycerides, cholesterol levels, blood pressure, and body mass index. It is therefore important for children to be given adequate opportunity for play to prevent them from these health problems. Professionals, especially teachers should strive to have their schools and centers recognized nationally by providing playground to increase daily play activities for children for their health. It is important to include motor play experiences in preschools to promote physical health. Low physical activity level in the early years predicts later health problems. Sedentary preschoolers are more likely to become obese in childhood and later as adults, ${ }^{6}$ observed that obesity is linked to diabetes, heart disease, and other medical conditions, sedentary behavior may impact young children's health. Smilansky, ${ }^{7}$ claims that, preschool-age children who exhibit low levels of play activity are found already to have greater health risk factors, such as higher triglycerides, cholesterol levels, blood pressure, and body mass index. It is therefore important for children to be given adequate opportunity for play to prevent them from these health problems.

\section{B. The importance of pre-school teacher's participation in children's play}

Teachers need to show children they care for them by participating in their play activities and by using play they should enhance children's learning and emotional well-being. This important aspect of child growth and development requires well motivated teachers for their full participation in children's activities, an issue that need to be looked at by all ECDE stakeholders. Early childhood teacher is the facilitator of play. The teacher facilitates play by providing appropriate play environments. He should ensure safety of children. Age and developmental levels must be carefully considered in the design and selection of materials. Once appropriate environments and materials are in place, regular safety checks and maintenance are needed to ensure that the equipment is sound and safe for continued play. Unfortunately this is not happening in most pre-school centers, something that is likely to affect children's proper growth and development. It is not clear if the level of pre-school teachers' motivation influences their use of play as a medium of instruction and participates in children's activities. Johnson \& Wardle argues that the participation of the teacher in a child's play during the early years can be useful in laying a solid foundation for the child. As a conclusion, rather than discussing whether a teacher should participate or not, meaningful discussion must be developed regarding what degree of participation is necessary as well as how and under what conditions this participation should be placed. As it is supported through the literature review and as the finding of this case study shows that teachers should be a model and a demonstrator instead of intervening 
the play by direct instruction. To give ideas about how teachers can be a model is discussed in this study at length.

These ideas can assist teachers in integrating play in the teaching process for the betterment of the children at cognitive, emotional and social level. Teachers need to foster productive play through providing enough time, creating safe indoor and outdoor environment. They also need to build new experiences to extend and enrich ideas for play as well as observing children before intervention. Teachers must be careful not to be too intrusive in children's play to help them to develop their inventiveness and creativity skills. Muthee $\&$ Murungi $^{5}$ observed that teachers facilitate play by working with children to develop rules for safe play activities. Discussion about the appropriate use of materials, the safe number of participants on each piece of equipment, taking turns, sharing, and cleaning up provides the children with information to begin their play activities. Teachers' use of play, as a medium of instruction, and participating in children's play; need to be ongoing because some children may need frequent reminders about rules. As facilitators of children's play, teachers should closely observe children during play periods not only for assessment purposes, but also to facilitate appropriate social interactions and motor behaviors. Children will need teacher assistance in joining a play group, modifying behavior, or negotiating a disagreement. Careful observation will help the teacher to decide when to offer assistance and what form that assistance should take. Unfortunately all the above important aspects are not in place. It is not known the level of pre-school teacher's motivation to use play as a medium of instruction and participate in children's play activities. These are what this study seeks to find out.

\section{C.Association between teachers' motivation and their participation in children's play activities.}

Motivation is "a set of energetic forces that originate both within as well as beyond an individual's being, to initiate work-related behavior and to determine its form, direction, intensity, and duration". According to Lock \& Lotham $^{6}$ Motivation is viewed as such an energetic force that energizes and directs a person to work. Well motivated teachers are likely to use play as a medium of instruction and participate fully in children's play activities. They are likely to be fully involved in planning age appropriate activities for children, organize on their sharing of play, turn taking and the direction to follow during play for safety. This goes in line with Brown \& Marchant ${ }^{2}$ equity theory of motivation, which calls for a fair balance to be struck between teachers' inputs (e.g., hard work, skill levels, tolerance, and enthusiasm) and their' outputs (e.g., salary, benefits, and intangibles such as recognition). According to the theory, a fair balance serves to ensure a strong and productive relationship between teachers' motivation and their overall participation in children's activities. The study was carried out to establish the influence of pre-school teachers' level of motivation to use play as a medium of instruction and participate in children's play activities.

\section{D.Demographic factors influencing teachers' active participation in children's Play activities.}

Creating conditions that motivate pre-primary teachers to initiate positive interactions with children and a physical environment that is conducive both to teachers' work and children's development is essential. Training teachers is important since most untrained teachers may not have adequate or the necessary skills and information to draft appropriate plans for children during play, ${ }^{8}$ and there seems to be a disparity between what scholars in the field would like teachers to do and what teachers actually do in school settings To create these conditions, pre-primary centre parents and communities who sponsor about $70 \%$ of the pre-primary centers in Kenya Waithaka ${ }^{4}$ need to participate to address what According her physical working conditions, salary, benefits, job security, and interpersonal relations are essential factors for teachers' motivation .Teachers with such conditions are likely to be highly motivated and ready to participate in children's play activities. This study seeks to establish the level of pre-school teachers' motivation to play in children's learning.

The teachers whose 'hygiene' needs are satisfied are likely to show great responsiveness, give encouragement to children and use less negative disciplinary techniques encouraging children be involved in free and active play activities. This has been demonstrated by Muthee \& Murungi, ${ }^{5}$ who have reported that preschool teachers whose 'hygiene' needs are satisfied, become warm, sensitive and nurturing. This is the high level of motivation required for high level of performance. As a result, children will develop positive emotional adjustments, cognitive, language and social skills during their play activities. Through this children are likely to display fewer behavioral problems and became socially competent. This will enhance the amount of teacher interaction with children which will benefit them especially during play activities. These positive child outcomes clearly demonstrate the need to motivate teachers. The key factors influencing pre-primary teacher motivation therefore needed to be established in order to guide Early Childhood Development Teachers' Motivation in Kenyan communities in areas where they need to concentrate their efforts. According to Waithaka, ${ }^{4}$ most preschool teachers work in "unhealthy psychological work environment", including unclear terms and conditions of service, low irregular salary. Lacking the necessary facilities, equipment and materials to promote teacher motivation and holistic development of children contribute to teachers less involvement and participation in children's play. It is not known if these condition influence pre-school teachers to use play as a medium of instruction and participates in children's play activities. According to Stiped, ${ }^{8}$ most public centers which support unfriendly work conditions characterized by, rough and slippery playground, small congested playground, poorly constructed play equipments and lack of adequate play materials are likely not to motivate teachers, hence low participation in children's play. In school settings, different types of play promote children's learning and development across different domains. ${ }^{7,8}$ However, this will not be possible if teachers who are not motivated do not use play as a curricular tool in their classrooms and outside classroom.

Teachers might not utilize play effectively for children's learning and development if they are not well motivated. This makes most of them not interested and aware of children's needs, do not know when and how to match play materials and activities with children's interests, and do not know when to provide children with new materials, props, or ideas to move children's play toward a more challenging and satisfying level. ${ }^{6}$ According to Griffing, ${ }^{9}$ in developing daily schedules, early childhood teachers operationalize how their viewpoints are enacted in their various programs. Despite the fact that teachers may assign time for play in their lesson plans, playtime is not routinely built into the program because teachers are not well motivated and generally hold diverse viewpoints about teaching; one that is child-centered and another that is teacher-directed. ${ }^{7}$ Early childhood teachers are expected to set up appropriate, stimulating environment for young children 
but when not well motivated, teachers decide to stand back and may not follow up with guidance, scaffolding, or supportive, responsive interactions with the children as they play Griffing, ${ }^{9}$ Some teachers find it difficult to participate in children's play and follow the flow of children's play activities due to lack of motivation. Waithaka, ${ }^{4}$ argued that elaborative interaction can support children's play behavior; less motivated teachers might devalue free play as a learning activity. Griffing, ${ }^{9}$ suggests that teachers have to observe what children are doing, support their efforts, and participate thoughtfully in order to promote additional learning. Thus, teachers can take part in children's play activities by being sensitive to children's needs. Waithaka, ${ }^{4}$ assert that if teachers interact with children during play, they would be able to enhance and manage children's play by matching children's play styles with their play activities.

The school context either nurtures or stifles teachers' motivation to use play because it determines the extent to which teachers provide children opportunities to play. In pre-primary educational settings, although teachers directly influence how children play, what they play with, how much they play, and the ways they play with each other are equally important. Since teachers are the first responders when children face challenges during play, it seems reasonable to explore their views and motivate them. Moreover, teachers' views are essential because they can provide valuable information that could be utilized to enhance children's learning experiences in pre-primary educational settings and considered when reviewing preschool programs.

\section{Summary of the literature review.}

Research finding has shown that, play serves an important process for promoting children's learning and development. It enhances emotional, intellectual, physical, and social skills of the child in ways that cannot be taught through formal classroom instruction. The study was done to establish the level of pre-school teacher's motivation to use play as a medium of instruction and participate in children's play activities. Playing a game is a way to guide children who have the basic knowledge about the world and this enables them to understand the world around them. It has shown the importance of teachers' motivation to their participation in children's play. Why teachers are not involved in children's play activities is what this study seeks to establish. Teachers have been proved to be important in scaffolding children's play and guiding them during play.

Well motivated teachers are likely to participate fully in children's play activities. They are likely to be fully involved in planning age appropriate activities for children, organize on their sharing of play, turn taking and the direction to follow during play for safety. It is not clear the level of pre-school teachers' motivation to use play as a medium of instruction in children's learning. When children are not given enough time and opportunities to play they are likely to have health problems, reasons, why teachers do not use play as a medium of instruction and participate in children's play activities should be established and solution sort. It is not clear if lacking the necessary facilities, equipment and materials to promote children's play, influence the level of teachers' motivation to use play as a medium of instruction for children's learning for children's holistic development.

\section{Methodology}

The study employed the descriptive research design, the independent variables were; pre-school teachers' level of motivation to use play as a medium of instruction and the teachers' demographic characteristics that included age, experience, the education level and teachers' training and the dependent variables were; teachers' use of play as a medium of instruction and their participation in children's play that included teachers' actual involvement in play, provision of play opportunities and play materials. The research was carried out in Masaba north District of Nyamira County Nyanza Province, Kenya. The district has varied economic potential and ecological zones, that is, Rigoma, Gesima and Gachuba zones with diverse residential areas ranging from upper middle class to informal settlements, high potential rural areas - comprising Mochenwa and Girango zones, moderately low agricultural potential zone of Bocharia. The district has four divisions with $93 \mathrm{ECDE}$ public centers and $36 \mathrm{ECDE}$ private centers.

The study employed stratified sampling method to achieve the desired sample sizes from various sub-sets in the population. The population was stratified into public, private, rural and urban preschools. From the target population of one hundred and twenty nine $(\mathrm{N}=129)$ pre-schools in Masaba north district, Nyamira county, a random sample of $(10 \%)$ pre-schools from each category was selected using the simple sampling procedure. This sample size was ideal for the researcher to be able collect data from a small sample for convenience and reduction of research costs. To distribute the random sample to all categories of preschools, a sample fraction (f) was calculated to give the probability of any categories of preschools being selected for the sample. The sample was defined by the equation $\mathrm{f}=$ random sample $/ \mathrm{N}$, that is, $13 / 129=0.101$. The number of preschools in each category was multiplied by the sample fraction $(\mathrm{f}=0.101)$ to obtain the sample size for every strata. The study sampling frame is as shown in Table 1.

Simple random sampling procedure using the lottery technique was used to get the sample size in every strata of the population as shown in Table 1 preschools in each stratum were given a number on small pieces of paper which were then folded, put in a container, mixed thoroughly and randomly picked one by one until the sample for each stratum was covered. This method had the benefit of yielding research data that was generalized to the larger population. One HT and one teacher from every preschool in the sample categories (a total of 34) were selected for the study. A total of 1148 preschoolers $(182(16 \%)$ in private, $392(34 \%)$ in public, $310(27 \%)$ in urban and 264(23\%) in rural preschools) were involved in the study.

\section{C.Pre-school teacher's motivation to use play as a medium of instruction?}

Using this question, the study purposed to establish the level of pre-school teacher's motivation that can influence them to use play as a medium of instruction. Pre-school Head Teachers, teachers and the researcher provided the information elicited from the different strata (categories) of preschools under study. This was measured using teachers' frequency of use of play as a medium of instruction and participation in children's' play activities (Table 2) revealed that out of 26 preschools under study (31\%)of private pre-school centers teachers use play as a medium of instruction and participate in play activities. $(23 \%)$ of Public pre-school centers teachers use play as a medium of instruction in the same time participate in children's' play activities. (19\%) of Urban pre-school centers teachers use play as a medium of instruction and participate in children's play activities while(27\%) of Rural pre-school centers teachers use play as a medium of instruction and participate in children's' play activities (Table 2). 
Table I Sampling grid

\begin{tabular}{lllllllll}
\hline $\begin{array}{l}\text { Pre- } \\
\text { school } \\
\text { category }\end{array}$ & $\begin{array}{l}\text { Target } \\
\text { population }\end{array}$ & N & $\%$ & \multicolumn{2}{l}{$\begin{array}{l}\text { Pre- } \\
\text { school }\end{array}$} & \multicolumn{2}{l}{ No. of H/T } & $\begin{array}{l}\text { No. of Pre- } \\
\text { scholars }\end{array}$ \\
& N & $\%$ & N & $\%$ & N & $\%$ \\
\hline Private & 4 & 15 & 4 & 15 & 11 & 15 & 182 & 16 \\
Public & 9 & 35 & 9 & 35 & 25 & 35 & 392 & 34 \\
Rural & 10 & 38 & 10 & 38 & 13 & 18 & 264 & 23 \\
Urban & 3 & 12 & 3 & 12 & 23 & 32 & 310 & 27 \\
Total & 26 & 100 & 26 & 100 & 72 & 100 & 1148 & 100 \\
\hline
\end{tabular}

Table 2 Showing teacher's participation in children's plays activities

\begin{tabular}{lll}
\hline Category & $\begin{array}{l}\text { Numbers of centers } \\
\text { involved in play } \\
\text { activities }\end{array}$ & Percentage \% \\
\hline Private & 8 & 31 \\
Public & 6 & 23 \\
Urban & 5 & 19 \\
Rural & 7 & 27 \\
Total & 26 & 100
\end{tabular}

\section{Pre-school teachers' level of motivation on use of play as a medium of instruction?}

Young children's desires to explore limits, venture into new experiences and develop their capacities emerge from a very early age thus enabling them to form their earliest experiences from play. Based on this fact, play must be used as a medium of instruction to enable children to explore, discover, experiment, manipulate and create basic information about the world. Smilansky ${ }^{7}$ argues that play is the "ultimate integrator of human experience" .He argues, through play, children to learn and enjoy as they develop and grow and learn how to use their muscles, coordinate what they see with what they do, and gain mastery over their body. The study findings confirmed the assumption that all the preschools $(100 \%)$ under study belief that there is a level of motivation of pre-school teachers to use play as a medium of instruction and participate in children's play activities. In response to the question on the influence of pre-school teachers level of motivation to use play as a medium of instruction? HTs and teachers were required to indicate whether there is a level of preschool teachers to use play as a medium of instruction participate in children's play activities. The responses from HTs and teachers are tabulated in Table below. From Table 3 teachers provide care and safety of children during play. (35\%) of the 52 respondents, $(21 \%)$ of the respondents observes that teachers promote children's learning and emotional well being.(12\%) observed that teachers facilitate children's play by providing appropriate play environment (19\%) stated that teachers model and demonstrate play activities and (13\%) reported teachers (Table 3 )
Table 3 Showing the influence of pre-school teachers' motivation to use play as a medium of instruction and participate in children's play activities?

\begin{tabular}{|c|c|c|}
\hline $\begin{array}{l}\text { Influence of } \\
\text { teachers level of } \\
\text { motivation to use } \\
\text { play as a medium } \\
\text { of instruction. }\end{array}$ & $\begin{array}{l}\text { Number of } \\
\text { respondents }\end{array}$ & Percentage \% \\
\hline $\begin{array}{l}\text { They provide } \\
\text { care and safety of } \\
\text { children during play. }\end{array}$ & 18 & 35 \\
\hline $\begin{array}{l}\text { They promote } \\
\text { children's learning } \\
\text { and emotional well } \\
\text { being }\end{array}$ & 11 & 21 \\
\hline $\begin{array}{l}\text { They facilitate } \\
\text { children's play } \\
\text { by providing } \\
\text { appropriate play } \\
\text { environment }\end{array}$ & 6 & 12 \\
\hline $\begin{array}{l}\text { They model and } \\
\text { demonstrate play } \\
\text { activities to children }\end{array}$ & 10 & 19 \\
\hline $\begin{array}{l}\text { Helps to develop } \\
\text { rules for children's } \\
\text { safe play activities. }\end{array}$ & 7 & 13 \\
\hline Total & 52 & 100 \\
\hline
\end{tabular}

E. Association between teachers' motivation and their use of play as a medium of instruction and participate in children's play activities

In this question, the researcher wanted to establish the kind of motivation required for the teachers to use play as a medium of instruction. The responses are summarized in the Table 4.

Table 4 Shows teachers motivators to use play as a medium of instruction

\begin{tabular}{lll}
\hline Motivation & Frequency & Percentages \% \\
\hline Salary & 14 & 27 \\
Good management & 11 & 21 \\
Personal convenience & 8 & 15 \\
Work load & 7 & 14 \\
Other benefits & 9 & 17 \\
No response & 3 & 6 \\
Total & 52 & 100
\end{tabular}

From the Table above $27 \%$ of the respondents regard salary as the main motivator of pre-school teachers. The amount of salary and increments received motivates teachers, this was received from 14 centres out of the 52 sampled centres. Those who cited salary as a motivator were happy about being paid on time and during the school holiday. The prioritized teacher motivators therefore, were consistent with the ranked levels. A part from salary, other motivator cited includes, school feeding program from which they got a share of the food. Personal convenience and manageable workload respectively were found to motivate teachers to use play as a medium of instruction. 
These included being near home, being near a town and living in an area where basic necessities are affordable.

Ndani, ${ }^{10}$ found out that working near home and relationships with pupils and other teachers motivates teachers to use play as a medium of instruction. Her findings are in harmony with the personal convenience and interpersonal relationships discussed above. While her study is limited to satisfaction of teachers to help pupils learn better, this study was more on teachers' level of motivation to use play as a medium of instruction and participate in children's play activities. For effective performance of teachers, they require good motivators cited above. Further, Waithaka, ${ }^{4}$ observed that, good learning atmosphere, management and salary paid on time to be satisfier of preschool teachers. In addition to the above, this study identified community recognition for good work, manageable workload and other benefits as motivators of preschool teachers. The same information is represented in the pie chart below Figure 1.
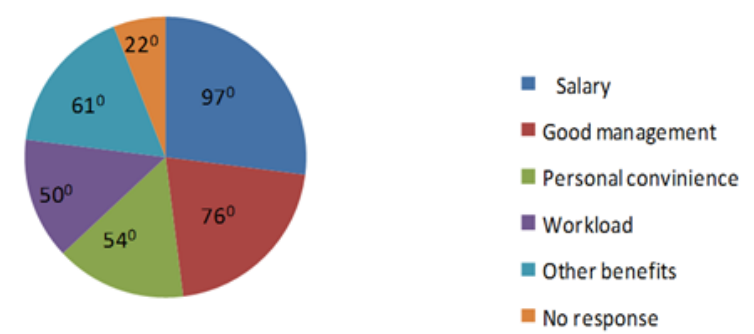

Figure I The pie chart showing teachers' motivators

\section{F. Demographic characteristics that influence pre- school teachers' to use play as a medium of instruction and participate in children's play?}

In this question, the researcher wanted to establish the kind of motivation required for the teachers to use play as a medium of instruction. The responses are summarized in Table 5. The data collected revealed that various demographic characteristic influence teachers to use play as a medium of instruction. (29\%) of the respondents gave age of teachers as the demographic characteristics that influence teachers to use play as a medium of instruction and participate in children's play activities. $(22 \%)$ gave the level of teachers' qualification as the demographic character influencing their participation. The type of training was given by $(20 \%)$ of the respondents. The years of teaching was given by $(16 \%)$ respondents while gender was given by $(13 \%)$ as one of the demographic characteristics that influence teachers to use play as a medium of instruction and participate in children's play activities (Table 5).

Table 5 Showing demographic factors influencing teachers to use play as a medium of instruction

\begin{tabular}{lll}
\hline Demographic factors & Responses & Percentages \% \\
\hline Age & 13 & 29 \\
Years of teaching experience & 7 & 16 \\
Level of qualification & 10 & 22 \\
Gender & 6 & 13 \\
Type of training & 9 & 20 \\
Total & 45 & 100 \\
\hline
\end{tabular}

\section{Summary of the findings}

The finding of the study revealed that $(35 \%)$ of the private preschools allowed children to participate in a variety of structured and unstructured activities and use play as a medium of instruction, (22\%) of the public pre-schools allowed children to participate in a variety of structured and unstructured activities and use play as a medium of instruction. (17\%) of the rural pre-schools allowed children to participate in a variety of structured and unstructured activities and use play as a medium of instruction, while $(26 \%)$ of the rural preschools allowed children to participate in a variety of structured and unstructured activities and use play as a medium of instruction. This revealed that it is the majority of the private pre-schools that allowed children to participate in play activities represented by $35 \%$ while rural pre-schools allow minimal opportunities for children's play activities. The findings revealed that the majority of teachers in rural pre-schools are less motivated to participate in children's play activities and use play as a medium of instruction. From the data collected it revealed the following as the motivator for teachers to use play as a medium of instruction. $(27 \%)$ gave good salary as one of the motivators of preschool teachers $(21 \%)$ gave good management $(15 \%)$ gave personal convenience and 7(14\%) gave reduced workload as motivators of preschool teachers.

The second objective explored the importance for pre-school teachers' participation in children's play activities? To determine how they influenced participation of preschool children in play activities. The study revealed that pre-scholars felt safe when they played in the presence of adults who in this case are teachers. It was found that this boosted their moral to participate in activities that were to their age, size, needs and ability as well as enhanced their physical, mental, social and moral development. It was evident from the study that despite the many academic involvement by teachers demanded by parents, teachers level of motivation given to them can influence their use of play as a medium of instruction and participate in children's play activities. Even if teachers neglect children's play in an attempt to maximize school time in academic pursuits, they can be motivated be motivators and encouraged to use play as a medium of instruction and participate in children's play activities. According to the research findings most respondents believed that adults' play with children is as important as children's play with their peers. Adults could help children engage in play that children could not do on their own. Teacher supported play is an important part of developmentally appropriate practice.

The third objectives examined the association between teachers' motivation and their use of play as a medium of instruction and participate in children's play activities? Teachers have a key role in fostering play, especially when they involve in supportive and appropriate ways in children's play. Research has described various teacher roles in supporting children's play. The study has shown which roles have positive and negative effects on play. It has categorized these roles under different terms. Teachers have facilitative roles that have positive effect on children's play they have supportive roles and constructive roles. Besides teachers' roles, they also provide interaction which encourages children's play. Pre-schools who paid well are greatly motivated and are ready to facilitate support children's learning activities. Teachers differed in the responses about the influence of good management in motivating them use play as a medium of instruction and in participating in children's play activities. Other factors, such as personal convenience, teachers work load and 
other benefits teachers get are some of the factors that influence teachers to use play as a medium of instruction and participate in children's play activities. It is evident from the study that teachers in pre-schools where teachers are provided with adequate motivators participate fully in children's play and general learning activities.

The fourth objective helped to establish the demographic characteristics that influence pre-school teachers to use play as a medium of instruction and participate in children's play? The study findings showed that various demographic characteristics influence teachers in different ways to use play as a medium of instruction. Teachers who are of middle age bracket are energetic and interested in children's play. Those who are well trained with long teaching experience have a wide knowledge on the play activities required by children who are at various levels of development for their holistic development. Teachers' level of qualification was also found as one of the demographic characteristics that determine their level of motivation to use play as a medium of instruction. Gender as a demographic characteristic does not very much influence teachers level of motivation because given level ground both male and female behave almost in the same manner in handling children's learning activities.

\section{Conclusion}

From the study it can be concluded that Play serves an important process for promoting children's learning and development. It enhances emotional, intellectual, physical, and social skills of the child in ways that cannot be taught through formal classroom instruction. Playing a game is a way to guide children who have the basic knowledge about the world and this knowledge open them a way to the language, creative/ art, social science, mathematics and music they will learn. It is essential to create conditions that motivate pre-primary teachers to initiate positive interactions with children and a physical environment that is conducive both to teachers' work and children's development. Motivating teachers is important since most less motivated teachers may not spare adequate time to draft appropriate plans for children's play activities, plan adequate play space, developmentally-appropriate play equipment and materials, proper surfacing of playgrounds, regular maintenance inspection or play areas and equipment and, activated supervision of children while at play. Preschool teachers whose 'hygiene' needs are satisfied, become warm, sensitive and nurturing. This high level of motivation is required for high level of performance. Various demographic characteristics also play great role in determining teachers' level of motivation, they include the age of the teacher, gender, and the teachers' level of qualification, years of teaching experience and the type of training a teacher went through. As a result, children will develop positive emotional adjustments, cognitive, language and social skills during their play activities. Through this children are likely to display fewer behavioral problems and became socially competent. This will enhance the amount of teacher interaction with children which will benefit them especially during play activities. Based on the results of this study, it can be concluded that despite the many challenges that constrain pre-school teachers' motivation to use play as a medium of instruction and participate in children's play activities, children continue to play because preschool teachers have some effort in participating in children's play activities and using play as a medium of instruction. A close relationship exists between teachers' level of motivation and their use of play as a medium of instruction and their participation in children's play activities.

\section{Recommendations of the study}

Use of play as a medium of instruction is a right issue aimed at strengthening children's participation in play activities. As a result, preschool teachers should be well motivated to find strategies that promote the rights of the young children as provided in the Convention of the Rights of Children (1989) and Children's Act (2001). These strategies should be followed to either minimize or eliminate risky conditions of leaving children in class for academic work that may retard their proper growth, development and psychological distress to young children. ${ }^{11-13} \mathrm{~A}$ well planned program to motivate pre-school teachers to use play as a medium of instruction and participate in children's play activities should be sort. This is likely to promote children's physical and psychological growth and development, while at the same time ensuring children's safety during their play activities. Preschool proprietors, managers, administrators, parents and other ECDE stakeholders should motivate pre-school teachers to use play as a medium of instruction. Provide adequate, safe, secure play materials and play ground spaces where children can effectively participate in play activities and thus acquire physical and psychosocial skills.

Focus on providing adequate and age appropriate play equipment and materials for all children, including those with special needs, within acceptable limits of safety. Age appropriate equipments and materials should be provided for different activities. The government should sensitize parents and the community to ensure that teachers are provided with the necessities to motivate to participate fully in children's learning activities. Intensify the supervision of children at play to ensure safe and inclusive participation in play activities. This can be done by the class teachers and other teachers who are well motivated. Introduce preschool programs which will encourage teachers to use play as a medium of instruction in every preschool centre with enough play materials and play ground safety as a major component to enable the teachers monitor and evaluate the safety status of children as they play on a daily basis.

\section{Acknowledgments}

None.

\section{Conflicts of interests}

Author declares that there is no conflict of interests.

\section{References}

1. Nabwire CO, Murungi CG. Influence of instructional strategies on preschool children's transition to lower primary school. A case of Kiambu County, Kenya. International journal of law, humanities \& social science. 2017.

2. Brown C, Marchant C. Play in practice: Case studies in young children's play, St. Paul, Minnesota: Redleaf Press. 2002.

3. Mweru M, Murungi CG. What can schools learn from children about use of culturally relevant methods and materials? Journal of Emerging Trends in Educational Research and Policy Studies. 2013;4(3).

4. Waithaka EN. Children's involvement in informal play activities in Kenya: A case study, Kiambu East and West districts. Kenyatta University. 2009.

5. Murungi CG, Muthee J. Relationship among intelligence, achievement motivation, type of school, and academic performance of kenyan urban primary school pupils. Encyclopedia of Information Science and Technology, $4^{\text {th }}$ Ed. 2017.

6. Locke EA, Latham GP. What should we do about motivation theory? Six 
recommendations for the twenty-first century. Academy of Management Review. 2004;29(3):388-403.

7. Smilansky S. Can adults facilitate play in children? Theoretical and Practical Consideration. Proceeding of a conference, Play: The Child Strives toward self-realization, Washington, DC: NAEYC. 1971;39-50.

8. Stiped D. Motivation to learn: From theory to practice. Englewood Cliffs, NJ: Prentice Hall. 1988.

9. Griffing P. Encouraging dramatic play in early childhood. In J.F. Brown (Ed.), Curriculum Planning for Young Children Washington, DC: NAEYC. 1982:38-47.
10. Ndani MN, Kimani EN. Factors influencing early childhood development teachers' motivation in Thika District, Kenya. Africa Journal of Teachers' Education. 2010;1(1):34-47.

11. Maslow AH. Motivation and Personality (2nd ed.). Harper and Row. New York. New York: John Wiley and Sons. 1970.

12. Mugenda O, Mugenda A. Research methods, Quantitative and qualitative. approaches. Nairobi: Acts Press. 1999.

13. Organizational Behavior and Human Performance. 2010;16:250-279. 